\title{
Biopatologia do Helicobacter pylori
}

\author{
Biopathology of Helicobacter pylori
}

\section{Marcelo Sady Plácido Ladeira ${ }^{1}$ \\ Daisy Maria Fávero Salvadori² Maria Aparecida Marchesan Rodrigues ${ }^{3}$}

\section{unitermos resumo}

Helicobacter pylori

Ilha de patogenicidade cag

Processo inflamatório

Espécies reativas de oxigênio

e nitrogênio
A infecção pelo Helicobacter pylori (H. pylori) induz inflamação persistente na mucosa gástrica com diferentes lesões orgânicas em humanos, tais como gastrite crônica, úlcera péptica e câncer gástrico. Os fatores determinantes desses diferentes resultados incluem a intensidade e a distribuição da inflamação induzida pelo H. pylori na mucosa gástrica. Evidências recentes demonstram que cepas do H. pylori apresentam diversidade genotípica, cujos produtos acionam o processo inflamatório por meio de mediadores e citocinas, que podem levar a diferentes graus de resposta inflamatória do hospedeiro, resultando em diferentes destinos patológicos. Cepas H. pylori com a ilha de patogenicidade cag induzem resposta inflamatória mais grave, através da ativação da transcrição de genes, aumentando o risco para desenvolvimento de úlcera péptica e câncer gástrico. O estresse oxidativo e nitrosativo induzido pela inflamação desempenha importante papel na carcinogênese gástrica como mediador da formação ou ativação de cancerígenos, danos no DNA, bem como de alterações da proliferação celular e da apoptose.

\section{abstract key words}

Helicobacter pylori (H. pylori)-infection causes persistent inflammation with different clinical outcomes in humans, including chronic gastritis, peptic ulcer, and gastric cancer. The key determinants of these outcomes are the severity and distribution of the $\mathrm{H}$. pylori-induced inflammation. Recent evidence has demonstrated that $\mathrm{H}$. pylori strains possess genotypic diversity whose products trigger inflammatory process and the main mediators and cytokines, which may engender differential host inflammatory responses with distintict clinical outcomes. H. pylori strains that possess the cag pathogenecity island induce more severe inflammation via activation of gene transcription, thus enhancing the risk for peptic ulcer and distal gastric cancer. The oxidative and nitrosative stress induced by inflammation plays an important role in gastric carcinogenesis as a mediator of carcinogen formation, DNA damage, and imbalances between cell proliferation and apoptosis.

\section{Helicobacter pylori}

Cag pathogenecity island

Inflammatory process

Reactive oxygen and nitrogen species
1. Pós-doutorando; doutor em Cenética; biólogo do Núcleo de Avaliação Toxicogenética e Cancerígen (Toxican) do Departamento de Patologia da Faculdade de Medicina de Botucatu da Universidade Estadual Paulista (FMB/Unesp).

2. Pesquisadora científica; doutora em Cenética; biomédica do Toxican e do Departamento de Patologia da FMB/Unesp.

3. Professora adjunta; livre-docente em Patologia; médica patologista do Departamento de Patologia da FMB/ Unesp.

Este trabalho foi realizado no

Toxican e no Departamento de Patologia da FMB/Unesp. Apoio financeiro: Fundação de Amparo à Pesquisa do Estado de São Paulo (Fapesp), bolsa de pósdoutorado 02/05043-5 e Conselho Nacional de Desenvolvimento e Pesquisa (CNPq), bolsa de Pesquisa 52189397-6. 
tos são presumivelmente precursores do câncer gástrico (19). Como somente uma minoria $(<1 \%)$ dos indivíduos infectados pelo $H$. pylori desenvolve câncer gástrico, suspeita-se de que fatores como a expressão de produtos bacterianos específicos, levando a diversos graus de resposta inflamatória, com diferentes freqüências de danos no DNA, possam estar relacionados à carcinogênese gástrica (55).

Vários estudos conduzidos em parentes de primeiro grau de pacientes com câncer gástrico têm destacado associação positiva entre história familial e risco para câncer gástrico $(9,19,66)$. Indivíduos infectados pelo $H$. pylori e com história de câncer gástrico familial podem apresentar risco até 16 vezes maior de desenvolvimento de câncer gástrico do que indivíduos não-infectados e sem história familial (66). Provavelmente tais indivíduos estão infectados pelas mesmas cepas de $\mathrm{H}$. pylori e apresentam resposta inflamatória similar. $\mathrm{O}$ aumento do risco para câncer gástrico pode estar relacionado a diferenças na expressão de produtos bacterianos específicos, a diferentes respostas do hospedeiro ou a diferentes interações entre a bactéria e o hospedeiro (56)

\section{Microbiologia do H. pylori}

O gênero Helicobacter foi definido por estudos de composição do RNA ribossômico (61), de seqüenciamento e hibridação do DNA da bactéria (28). Este gênero, juntamente com outros (Campylobacter, Arcobacter e Wolinella), constitui a superfamília VI de bactérias gram-negativas definidas por Vandamme et al. (74).

A morfologia do $H$. pylori, observada à microscopia ótica e eletrônica, é homogênea, apresentando-se com estrutura encurvada ou espiralada, de superfície lisa e extremidades arredondadas, móvel, não-esporulada e microaerófila. Mede aproximadamente $0,5 \mu \mathrm{m}$ a $0,1 \mu \mathrm{m}$ de largura e $3 u \mathrm{~m}$ de comprimento, possuindo de quatro a seis flagelos unipolares embainhados e bulbos terminais nas extremidades lisas.

O gênero Helicobacter é composto atualmente de, no mínimo, 27 espécies que compartilham propriedades comuns, especialmente aquelas relacionadas com a vida no estômago, onde podem localizar-se no fundo e no corpo, mas é principalmente no antro onde as bactérias são encontradas em maior densidade (8). O H. pylori pode distribuir-se de maneira focal, segmentar ou difusa ao longo da mucosa gástrica (77), localizando-se no interior ou sob a camada de muco que recobre o epitélio da superfície ou das fovéolas, em íntimo contato com a membrana luminal das células epiteliais que revestem a mucosa gástrica.

O H. pylori possui capacidade excepcional de aderência (72). É adaptado para colonizar somente a mucosa gástrica, sendo observado raramente em áreas de metaplasia intestinal. No duodeno, a bactéria coloniza áreas de metaplasia gástrica $(47,59)$, fator de grande importância para seu papel na patogênese da úlcera péptica duodenal. A afinidade do $H$. pylori pelas células mucíparas gástricas deve-se à composição neutra do muco gástrico, diferente dos mucopolissacarídeos ácidos produzidos pelas células caliciformes da metaplasia intestinal (59).

\section{Epidemiologia e transmissão}

A gastrite induzida pelo $H$. pylori é uma das infecções mais comuns na espécie humana, comprometendo cerca de metade da população mundial (8). A bactéria apresenta distribuição cosmopolita, sendo encontrada em habitantes dos cinco continentes $(27,57)$. A prevalência da infecção pelo $H$. pylori varia com a idade, o nível socioeconômico e a raça. Estudos sorológicos demonstraram que a prevalência de infecção por $H$. pylori aumenta com a idade e é maior nos países em desenvolvimento (44). $\mathrm{Na}$ França, a soropositividade em indivíduos menores de 18 anos é de 7\%, enquanto na Argélia e na Costa do Marfim, está em torno de $62 \%$ e $64 \%$, respectivamente (49).

A infecção pelo $H$. pylori, em países desenvolvidos, ocorre após os três ou cinco anos de idade; já em países em desenvolvimento, crianças com menos de um ano podem estar contaminadas $(11,49)$. Em estudo realizado em Belo Horizonte com indivíduos entre sete meses e 16 anos, observou-se que o indivíduo mais jovem infectado tinha 3 anos e que a positividade de infecção pela bactéria aumentava com a idade, atingindo $82 \%$ dos indivíduos maiores de 12 anos (11). Estes dados são similares aos encontrados por Coelho et al. (12) em adultos sintomáticos na mesma cidade. A grande maioria dos pacientes, nos dois estudos, era de baixo nível socioeconômico.

Estudos brasileiros encontraram as seguintes prevalências: 59,5\% no Rio de Janeiro (RJ) (68); 76,3\% em São Paulo (SP) (23); 83\% em Santa Maria (RS) (50); 84,7\% em Nossa Senhora do Livramento (MT) (69); 85,18\% em Botucatu (SP) (39); 87\% em Araçuaí (MG) (52); 89,6\% em Campinas (SP) (45) e 96\% em São Luís (MA) (7).

Embora cerca de $50 \%$ da população mundial estejam contaminados pelo $\mathrm{H}$. pylori, os mecanismos de transmissão 
constituem motivo de muita controvérsia. As vias oral-oral e fecal-oral parecem ser as principais formas de transmissão. Entretanto as taxas reais não foram estabelecidas (48).

Klein et al. (38) sugeriram que a água contaminada por matéria fecal constitui importante fonte de infecção. Em 1994, Kelly et al. (37) conseguiram isolar a bactéria das fezes de indivíduos colonizados. Recentemente foi relatado que o $\mathrm{H}$. pylori pode ser transmitido sexualmente por via oral-anal (21).

Segundo Bujanover et al. (10), a aglomeração intrafamilial também é um fator importante. Drumm et al. (18) obtiveram sorologia positiva em mais de $80 \%$ de irmãos colonizados com a bactéria. Malaty et al. (46) constataram maior incidência de crianças com $\mathrm{H}$. pylori, filhos de pais infectados, em relação a crianças cujos pais não eram portadores deste microorganismo. Langenberg et al. (41) relataram o risco de transmissão da bactéria através da endoscopia.

Além das causas ambientais que contribuem para a transmissão do $H$. pylori, há estudos que indicam que fatores do hospedeiro exercem importante papel nas taxas de infecção e nas conseqüências patológicas induzidas pelo microrganismo $(3,36,62)$.

\section{Patogênese e fatores de virulência do H. pylori}

O resultado clínico da infecção pelo $H$. pylori é determinado pela complexa interação entre fatores do hospedeiro e da bactéria. Enquanto os fatores do hospedeiro permanecem desconhecidos, a identificação dos da bactéria avança continuamente.

A resistência ao ácido clorídrico é de vital importância na patogênese do $H$. pylori, visto que, sem este atributo biológico, a bactéria não teria condições de colonizar a mucosa gástrica. A enzima urease, que é uma proteína de alto peso molecular (500 a 600KDa), atua promovendo a hidrólise da uréia, presente em condições fisiológicas no suco gástrico, levando à produção de amônia. Esta atua como receptor de íons $\mathrm{H}^{+}$, gerando $\mathrm{pH}$ neutro no interior da bactéria, o que confere ao $H$. pylori resistência à acidez gástrica (79). Desta maneira, a bactéria fica protegida dos efeitos deletérios do $\mathrm{pH}$ ácido do estômago. A urease compreende $6 \%$ do total de proteínas sintetizadas pela bactéria, o que representa grande investimento energético motivado pela sua ação essencial como fator de colonização (35).

A maior parte da urease sintetizada pela bactéria situa-se em seu citoplasma. A produção de amônia depen- de da entrada de uréia na bactéria, que é controlada por uma proteína de membrana sensível ao pH. Esta proteína é codificada por um gene da família urease, conhecido como urel $(76,78,79)$. Cepas do H. pylori com deleção de urel não sobrevivem em $\mathrm{pH}$ ácido. Weeks et al. (78) demonstraram que a entrada de uréia na bactéria é acelerada em pH 5 e diminuída em pH 7. A entrada de uréia é altamente específica, não sendo facilmente saturada, e independe de temperatura e energia $(76,79)$. Portanto o H. pylori possui um mecanismo que permite a liberação do substrato uréia sobre a urease em condições em que é necessária a alcalinização local do meio ambiente. A proteína urel atua como portão de um canal, que também permite o refluxo de urease, aumentando o $\mathrm{pH}$ periplasmático e do microambiente próximo, prevenindo acúmulo tóxico de uréia dentro da bactéria $(76,79)$.

A bactéria, na fase precoce de colonização, necessita atravessar a camada de muco que protege o epitélio gástrico. Tal camada é formada por um gel viscoelástico que confere proteção química e mecânica ao revestimento epitelial, inclusive contra bactérias (35). No entanto lipases e proteases sintetizadas pelo $\mathrm{H}$. pylori degradam a camada de muco, facilitando a progressão da bactéria. Além disso, o H. pylori move-se facilmente devido à morfologia em espiral e aos flagelos e, assim, atravessa a camada de muco, estabelecendo íntimo contato com as células epiteliais de revestimento (35). Outras enzimas, sintetizadas pela bactéria, tais como superóxido dismutase, catalase e arginase, conferem proteção contra a atividade lítica de macrófagos e neutrófilos, impedindo uma resposta eficaz do hospedeiro (30).

\section{Genes do H. pylori associados à virulência}

Até o presente, a biotipagem, a análise do genoma e a diversidade plasmídica permitiram a identificação de cerca de quarenta cepas da bactéria não-relacionadas epidemiologicamente. As variações genômicas das cepas podem ser responsáveis pela codificação de diferentes fatores de virulência, capazes de determinar diversos tipos de lesão no hospedeiro (8).

\section{Gene cagA}

O primeiro gene cepa-específico identificado no $H$. pylori foi o citotoxin antigen associated ( $\operatorname{cag} A)$, que está fortemente associado ao risco para desenvolvimento de câncer gástrico (56). As cepas $\operatorname{cag} A^{+}$tendem a ser mais viru- 
lentas e induzem níveis mais altos de expressão de citocinas, tais como IL-1b e IL-8 (8). Parsonnet et al. (54) mostraram que pacientes infectados por cepas que expressam cagA têm probabilidade três vezes maior de desenvolver câncer gástrico do que aqueles infectados por cepas cagA-. O gene cagA é considerado marcador da ilha de patogenicidade cag (cag-PAl), que possui de 35 a 40Kb, comporta 31 genes (8) e é encontrada em cerca de $60 \%$ das cepas ocidentais. A ilha cag-PAl é um componente do genoma do $H$. pylori que contém genes homólogos aos de outras bactérias que codificam componentes do sistema de secreção do tipo IV, que atua como agulha e serve para injetar moléculas efetoras da bactéria na célula hospedeira, permitindo que a bactéria module vias do metabolismo celular da célula hospedeira, incluindo a expressão de proto-oncogenes $(14,15)$.

Recentemente, quatro grupos de pesquisadores $(1,53$, $65,70)$ demonstraram que componentes do $H$. pylori induzem alterações na fosforilação de tirosinas, nas vias de sinalização e de transdução da célula hospedeira, resultando em rearranjos do citoesqueleto e alterações morfológicas que estimulam a célula a se espalhar e se alongar de maneira idêntica à produzida pelo fator de cres- bactéria podem induzir a desfosforilação de proteínas normalmente fosforiladas (5).

A proteína $\operatorname{cagA}$ do $H$. pylori atua como antígeno altamente imunogênico. A estrutura do gene revela uma região 5' altamente conservada, mas com uma região 3' com número variável de seqüências repetitivas, o que leva à variação do comprimento da proteína. Como a proteína CagA é fortemente imunogênica, qualquer variação em seu comprimento pode levar a diferentes respostas do hospedeiro, incluindo diferentes graus de resposta inflamatória.

Yamaoka et al. (80) estudaram a variabilidade da região $3^{\prime}$ do gene cagA para investigar se diferenças nesta região estariam relacionadas a diferentes processos patológicos. Estes autores constataram que $86 \%$ de uma das variantes eram provenientes de pacientes com câncer gástrico e concluíram que outras diferenças na região $3^{\prime}$ do gene $\operatorname{cag} A$ podem estar relacionadas a diferentes processos patológicos.

\section{Gene vacA}

A colonização da mucosa gástrica pelo $H$. pylori requer um complexo processo adaptativo. O fator-chave, que permite à bactéria sobreviver à acidez gástrica e atravessar o lúmen do estômago, é a enzima urease, que converte a uréia em amônia e bicarbonato (73). Para isso é necessária a produção da citotoxina vacA, que induz a formação de canais seletivos de ânions nas células epiteliais, levando à exsudação de uréia para a luz da mucosa gástrica. A vacA é considerada importante fator de virulência, visto que contribui para a produção de alcalóides pela urease, que podem induzir danos no DNA $(16,63,73)$.

O gene vacA está presente em todas as cepas do $H$. pylori e compreende duas partes variáveis, s e $m$ (Figura 2). A região $s$ (codifica o sinal peptídico) está localizada no final da cadeia $5^{\prime}$ e possui dois alelos, $s 1$ ou $s 2$, sendo que para o alelo $s 1$ existem três subtipos: $s 1 a$, s1b e $s 1 c$; a região média $(m)$ possui os alelos $m 1$ ou $m 2$ (2). A combinação em mosaico dos alelos da região $s$ com os alelos da região $m$ determina a produção de citotoxinas, responsáveis pelo grau de virulência da bactéria. As cepas portadoras do genótipo vacA $51 / \mathrm{m} 1$ produzem grande quantidade de toxina, enquanto as cepas $51 / \mathrm{m} 2$ produzem quantidade moderada, e as cepas $s 2 / m 2$, pouca ou nenhuma toxina. As cepas vacA do tipo s1a parecem ser mais patogênicas que as $s 1 b$ e $s 1$ c ou $s 2$, sendo mais relacionadas à úlcera péptica. As cepas do tipo $m 1$ estão associadas a maior risco de danos às células epiteliais do que as do tipo $m 2(4,75)$.
Figura 1 - Microscopia de contraste de fase. (A) Células normais da linhagem celular de adenocarcinoma gástrico (ACS); (B) células ACS após $30 h$ de infecção pelo H. pylori. Adaptado de Segal et al. (65) 


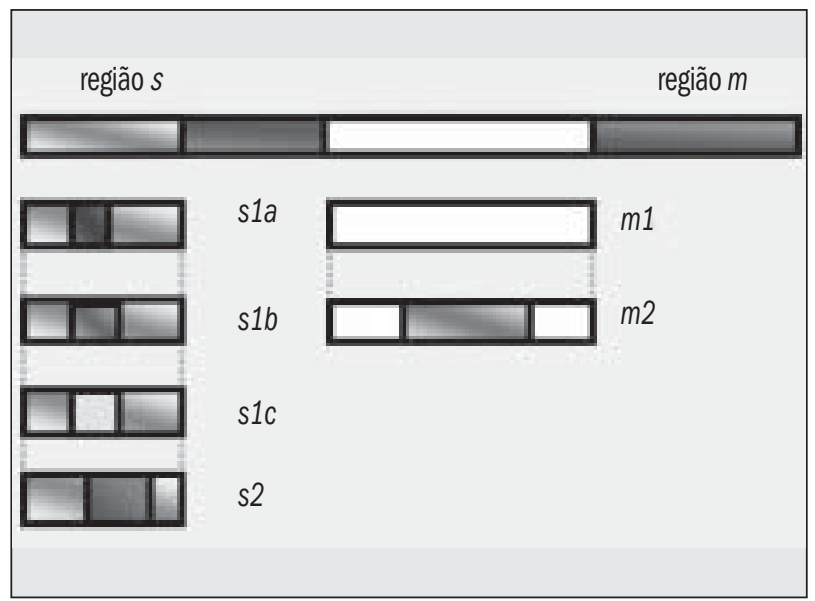

Figura 2 - Mosaico do gene vacA. Adaptado de Atherton et al. (2)

\section{Gene babA}

Fatores de aderência da bactéria ao epitélio gástrico favorecem a colonização e contribuem para sua patogenicidade (58). O fator de aderência blood group antigen adhesin (babA) ligado ao grupo sangüíneo Lewis ${ }^{\mathrm{b}}$ foi descoberto recentemente (31). Ele pode ser um importante produto de patogenicidade ao permitir o contato entre a bactéria e o epitélio e facilitar a liberação de fatores de virulência como cagA e vacA. O gene babA possui dois alelos distintos: babA1 e babA2. Em 1999, Gerhard et al. (26) demonstraram associação entre o alelo babA2 e a presença de úlcera péptica e adenocarcinoma gástrico.

\section{Gene cagE}

O predomínio de neutrófilos na mucosa gástrica, observado em pacientes infectados por cepas cag-PAl ${ }^{+}$, é ligado ao aumento de secreção de interleucina-8 (IL-8) secretada pelas células epiteliais da mucosa gástrica. Entretanto cepas cagA negativas também induzem aumento da secreção de IL-8 (60). Isto se deve ao fato de que a proteína cagA não atua diretamente sobre a IL-8. O gene ligado ao aumento da produção de IL-8 é o cagE, que é um dos genes da ilha cag (51).

\section{Gene iceA}

Recentemente, outro gene do H. pylori foi descrito e denominado induced by contact with epithelium (iceA). Existem dois alelos deste gene: iceA1 e iceA2. A função de iceA1 não está clara, mas este alelo apresenta forte homologia com a endonuclease de restrição do tipo II da Neisseria lactamica. Sua expressão é regulada pelo contato do H. pylori com as células epiteliais da mucosa gástrica. A expressão deste alelo é associada à úlcera péptica e ao câncer gástrico (56). A função do alelo iceA2 também é desconhecida.

\section{Gene HP-NAP}

A gastrite induzida pelo $H$. pylori é caracterizada por infiltrado inflamatório constituído por neutrófilos, linfócitos, plasmócitos e macrófagos. A intensidade da inflamação correlaciona-se com a severidade dos danos induzidos à mucosa e ao DNA $(39,40)$. Em 1995, Evans Jr. et al. (22) descreveram o gene neutrophils-activating protein (HP-NAP) do H. pylori e relacionaram sua expressão ao potencial de indução de inflamação, mesmo em cepas cagA negativas. O produto do gene HP-NAP induz aderência de neutrófilos às células endoteliais e estimula a produção de espécies reativas de oxigênio e nitrogênio pelos neutrófilos (64).

\section{Fatores do hospedeiro}

A resposta imune adequada consiste em eliminar o agente agressor sem comprometer a integridade e a função do órgão envolvido (20). Durante a infecção pelo $H$. pylori há predomínio de células Th1, enquanto as Th2 estão praticamente ausentes. Isto resulta em resposta imune inadequada, que não consegue eliminar o microorganismo. Além disso, células Th1 induzem a produção de anticorpos e citocinas, que contribuem para o aumento do processo inflamatório, com conseqüentes danos às células do hospedeiro. Fox e Wang (24) demonstraram que camundongos $\mathrm{p} 53^{+/-}$, infectados por Helicobacter felis, apresentaram resposta Th1 mais amena e menor risco de desenvolvimento de câncer gástrico.

\section{Interleucinas e câncer gástrico}

Alguns estudos têm indicado que a infecção pelo H. pylori induz inflamação por vários mecanismos, entre eles o contato direto com as células epiteliais, a estimulação e a liberação de citocinas. Pacientes infectados pelo H. pylori apresentam altos níveis de expressão e produção de IL1- $\beta$, IL-6, IL-8 e TNF- $\alpha(19,32,66)$.

O cluster do gene da interleucina-1 (IL-1), localizado no braço longo do cromossomo 2 , contém três genes relacionados dentro de uma região de 430kb: IL-1A, IL-1B e IL-1 RN, que codifica as citocinas pró-inflamatórias IL-1 $\alpha$ e 1L-1 $\beta$. A IL-1 $\beta$ é um importante fator de iniciação e amplificação da resposta inflamatória, e atua como poderoso inibidor de secreção ácida (hipocloridria). 
Vários estudos relatam que o $\mathrm{H}$. pylori ativa o gene NF- $\mathrm{KB}$ de células epiteliais da mucosa gástrica in vivo e in vitro (51). Este gene codifica um fator de transcrição que ativa a produção de interleucinas. A translocação nuclear de NF-KB é seguida do aumento da expressão de IL-8 (51). A IL-8, potente ativadora de neutrófilos, tem seu nível de expressão gênica relacionado à intensidade da gastrite. In vitro, o H. pylori estimula a liberação de IL-8, e estes eventos requerem interação entre a bactéria e as células epitelias da mucosa gástrica, que, através deste mecanismo, estimulam a quimiotaxia de neutrófilos.

Neutrófilos ativados geram espécies reativas de oxigênio e/ou de nitrogênio, que podem induzir danos oxidativos no DNA e danos às células epiteliais, as quais incluem peroxidação lipídica e oxidação de proteínas, levando a alterações do turnover celular (32). A taxa de proliferação de células epiteliais gástricas de pacientes infectados pelo $H$. pylori é significativamente mais alta do que a de indivíduos não-infectados (32). A infecção crônica pela bactéria induz aumento dos índices de apoptose, que podem acelerar a progressão para gastrite atrófica, com conseqüente aumento do risco para desenvolvimento de câncer gástrico (32).

Vários trabalhos destacam a importância da expressão de interleucina-6 (IL-6) e da cicloxigenase-2 (Cox-2) na inibição de apoptose em células da mucosa gástrica de pacientes infectados por $H$. pylori $(42,71)$. Esta redução da morte celular por apoptose, acompanhada por hiperproliferação, pode levar ao acúmulo de mutações, contribuindo para a gênese do câncer gástrico (32).

\section{H. pylori e danos oxidativos}

A alteração histológica mais evidente na mucosa gástrica, induzida pela presença do H. pylori, é a resposta inflamatória, cuja atividade depende da capacidade de resposta do hospedeiro e da atividade bacteriana (32). Nos processos inflamatórios, diferentes fagócitos, tais como neutrófilos, macrófagos e eosinófilos, geram radicais livres em resposta a mediadores pró-inflamatórios e produtos da parede celular bacteriana (67). Os radicais livres de oxigênio gerados no processo inflamatório reagem com o DNA e podem induzir alteração da expressão de proto-oncogenes (17), bem como gerar produtos genotóxicos como 8-hidroxinonenal ou malondialdeído, capazes de interagir com alvos moleculares no DNA, ou podem converter pró-carcinógenos em cancerígenos (17).
A instabilidade genômica demonstrada pela instabilidade de microssatélites (MSI) é observada em 13\%-44\% dos casos de câncer gástrico. A maioria das MSI de alto nível é associada a defeitos do sistema de reparo (29), que podem ser induzidos por radicais livres de oxigênio $(25,43)$.

Baik et al. (6) encontraram altos níveis de danos oxidativos no DNA de células da mucosa gástrica na fase precoce de infecção pelo $\mathrm{H}$. pylori. Os autores destacaram que estes resultados favorecem a hipótese de que a infecção pelo $H$. pylori seja o denominador comum entre a gastrite crônica e o carcinoma gástrico.

\section{H. pylori e síntese de óxido nítrico}

As espécies reativas de oxigênio e nitrogênio podem ter importante papel na carcinogênese gástrica por induzir danos no DNA direta ou indiretamente (33). As espécies reativas de nitrogênio são derivadas da síntese de óxido nítrico e induzidas por citocinas liberadas pelas células mononucleares da inflamação (34). Pacientes infectados pelo $H$. pylori apresentam altos níveis de expressão da enzima óxido nítrico-sintase induzível (iNOS) (66).

O óxido nítrico pode favorecer o acúmulo de mutações potencialmente oncogênicas por mecanismos como a inibição das enzimas do sistema de reparo, como hOGG1, que é responsável por mais de $95 \%$ da atividade da via de reparo por excisão de base (BER), tal como a excisão de 8-hidroxideoxiguanosina, que é o principal produto da atuação dos radicais livres. O óxido nítrico leva à inativação do processo de apoptose pela nitrosilação de proteínas pró-apoptóticas, tais como p53 e caspases, permitindo desta forma a sobrevivência de células com danos no DNA (33).

\section{Considerações finais}

As diferentes lesões orgânicas relacionadas à infecção pelo $H$. pylori resultam da interação entre os fatores de virulência da cepa infectante e a resposta inflamatória do hospedeiro. Novas tecnologias já disponíveis deverão acelerar o progresso da pesquisa nesta área e oferecer métodos mais efetivos de investigação da biopatologia da infecção pelo $H$. pylori . O uso de tecnologias que permitam a análise do padrão de expressão de genes da bactéria e do hospedeiro facilitará a identificação de indivíduos suscetíveis ao desenvolvimento de câncer gástrico, bem como de novos caminhos terapêuticos. 


\section{Referências}

1. A sahi, M . et al. Helicobacter pylori cagA protein can be tyrosine phosphorylated in gastric epithelial cells.J.Exp.Med., 191(4): 593-602, 2000.

2.A therton,J.C . et al. M osaicism in vacuolating cyto toxin alleles of H elicobacter pylori. J. Biol. Chem., 270(30): 17771-7, 1995.

3.A therton, J.C .The clinical relevance of strain types of $\mathrm{H}$ elicobacter pylori. Gut, 40: 701-3, 1997.

4.A therton, J.C . et al. Simple and accurate PCR-based system for typing vacuolating cytotoxin alleles of H elicobacter pylori. J. Clin. Microbiol., 37 (9): 2979-82, 1999.

5. A therton, J.C. C agA : a role at last. Gut, 47(3): 330-1, 2000.

6. Baik S.C. et al. Increased oxidative DNA damage in infected human gastric mucosa. Cancer Res., 56: 1279-82, 1996.

7. Bezerra, J.M et al. Infecção gástrica por Helicobacter pylori em pacientes sintomáticos da ilha de São Luís, MA : correlação endoscó pica, anato mo pato ló gica e microbiológica. Rev. Soc. Bras. Med.Trop., 29(3): 245-50, 1996.

8. Blaser, M.J. \& Berg, D.E. Helicobacter pylori genetic diversity and risk of human disease. J. Clin. Invest., 107(7): 767-73, 2001.

9. Brenner, H.; Bode, G. \& Boeing, H. Helicobacter pylori infection among offspring of patients with stomach cancer. Gastroenterology, 118:31-5, 2000.

10. Bujanover,Y. et al. Helicobacter pylori e doença péptica no paciente pediátrico. Clin. Ped. Am. N orte, 7:215-35, 1997.

11.C arvalho,A S.T. et al.D iagno sis and distribution of H elicobacter pylori in the gastric mucosa of symptomatic children. Brazilian J. Med. Biol. Res., 24: 163-6, 1991.

12. Co elho, L.G.V.; Das, S.S \& Karim, Q .N . Campylobacter pyloridis in the upper gastrointestinal tract: a Brazilian study. Arq. Gastroenterol., 24(1): 5-9, 1987.

13. Correa, P. Human gastric carcinogenesis: a multistep and multifactorial process. First A merican Cancer Society A ward Lecture on Cancer Epidemiology and Prevention. Cancer Res., 52: 6735-40, 1992.

14. Covacci, A. et al. Helicobacter pylori virulence and genetic geo graphy. Science, 284: 1328-33, 1999.

15.C ovacci,A \& Rappuoli,R.Tyrosine-phosphorylated bacterial proteins: Trojan horses for the host cell.J. Exp. M ed., 191: 587-92, 2000.

16. Debellis, L. et al. Helicobacter pylori cytotoxin vacA increases alkaline secretion in gastric epithelial cells. Am. J. Physiol. Gastrointest. Liver Physiol., 281(6): G 1440-8, 2001.

17. Drake, I.M. et al. Ascorbic acid may protect against human gastric cancer by scavenging mucosal oxygen radicals. Carcinogenesis, 17(3): 559-62, 1996.

18. Drumm, B. et al. Intrafamilial clustering of Helicobacter pylori infection. N. Engl. J. Med., 22: 359, 1990.

19. El-O mar, E.M. et al. Increased prevalence of precious changes in relatives of gastric cancer patients: critical role of $\mathrm{H}$. pylori. Gastroenterology, 118: 22-30, 2000.

20. Ernst, P.B.; Crowe, S.E. \& Reyes, V.E. How does Helicobacter pylori cause mucosal damage?The inflammatory response. Gastroenterology, 113(suppl. 6): S35-42, 1997.

21. Eslick, G. Sexual transmission of Helicobacter pylori via oralanal intercourse. Int. J. Std.Aids, 13 (1): 7-11, 2001.

22. Evans Jr., D.J et al. C haracterization of $\mathrm{H}$ elicobacter pylori neutro philactivating protein. Infect. Immun., 63(6): 2213-20, 1995.
23. Ferrari Jr.,A .P.; G eocze, S.\&Trabulsi, L.R. Campylobacter pylori in dispeptic patients. Rev. Hosp. S. Paulo/Esc. Paul. Med., 1(2): 65-8, 1989.

24.Fox, J.G \& \&W angT.C. H elicobacter pylori infection: pathogenesis. Curr. Opin. Gastroenterol, 18: 15-25, 2002.

25. Gasche, $C$. et al. 0 xidative stress increases frameshift mutations in human colorectal cancer cells. Cancer Res., 61: 7444-8, 2001.

26. Gerhard, M . et al. C linical relevance of the Helicobacter pylori gene for blood-group antigen adhesin. Proc. N atl. Acad. Sci. USA, 96: 12778-83, 1999.

27. Go, M.F. Review article: natural history and epidemiology of Helicobacter pylori infection. Aliment. Pharmacol. Ther., 16 (suppl. 1): 3-15, 2002.

28. Goodw in, C .S. et al. Campylobacter pylori become Helicobacter pylori. Int. J. Bacteriol., 39: 353-405, 1989.

29. Halling, K.C . et al. O rigin of microsatellite instability in gastric cancer. Am. J. Pathol., 155(1): 205-11,1999.

30. H azell, S.L.; Evans, D.J.\& Graham, D.Y . H elicobacter pylori.J. Gen. Microbiol., 137: 57-61, 1991.

31. Ilver, D. et al. Helicobacter pylori adhesin binding fucosylated histo-blood group antigens revealed by retagging. Science, 279: 373-9, 1998.

32. Israel, D.A. \& Peek, R.M. Review article: pathogenesis of Helicobacter pylori-induced gastric inflammation. Aliment. Pharmacol.Ther., 15: 1271-90, 2001.

33. DN A damage and inhibit D N A repair in cholangiocarcinoma cells by a nitric oxide dependent mechanism. Cancer Res., $60: 184-90,2000$.

34. Jaiswal, M . et al. H uman 0 ggl, a protein involved in the repair of 8-oxoguanine, is inhibited by nitric oxide. Cancer Res., 61:6388-93, 2001.

35. Jenks, P.. \& Kusters,J.G .Patho genesis and virulence of Helicobacter pylori. Curr. Opin. Gastroenterol., 16(suppl. 1): S11-8, 2000.

36. Kapadia, C.R. Host factors in Helicobacter infection. Gastroenterology, 113 (1): 361-2, 1997.

37. Kelly, S.M., Pitcher, M.C.L. \& Farmery, S.M. Isolation of Helicobacter pylori from feces of patients with dyspepsia in the U nited Kingdom. Gastroenterology, 107(6):1671-4,1994.

38. Klein, P.D.; Graham, D.Y. \& G aillour, G.L.W ater source as risk factor for Helicobacter pylori infection in Peruvian children. Lancet, 337(8756): 1503-6, 1991.

39. Ladeira, M.S.P. Estudos, pelo Ensaio Cometa, dos danos no DNA de células da mucosa gástrica de portadores de gastrite crônica, infectados ou não pelo Helicobacter pylori. Dissertação de mestrado. Instituto de Biociências, Universidade Estadual Paulista. Botucatu, 1997.

40. Ladeira, M.S.P. Estudo dos danos no DN A de células epiteliais da mucosa gástrica de pacientes com gastrite crônica, úlcera péptica e câncer gástrico, infectados ou não pelo H elicobacter pylori. Botucatu, 2002. Tese de doutorado. Instituto de Biociências, U niversidade Estadual Paulista.

41. Langenberg, W.; Rauws, E.A.J. \& O udbrier, J.K. Patient to patient transmission of Campylobacter pylori infection by fiberoptic gastroduo denosco py and biopsy.J. Infect. Dis., 161:507,1990.

42. Lin, M. et al. IL-6 inhibits apoptosis and retains oxidative DN A lesions in human gastric cancer AGS cells through up- 
regulation of anti-apoptotic gene $\mathrm{mcl}-1$. Carcinogenesis, 22(12): 1947-53, 2001.

43. Loeb LA.A mutator phenotype in cancer. Cancer Res., 61(8): 3230-9, 2001.

44. Logan, R.P.H.\&W alker, M.M.ABC of the upper gastrointestinal tract: epidemiology and diagnosis of Helicobacter pylori infection. Brit. Med. J., 323: 920-3, 2001.

45. Magalhães,A.F.N .et al. Gastrite crônica associada ao Helicobacter pylori em pacientes com dispepsia não-ulcerosa e com úlcera duodenal. Rev. Paul. M ed., 109(5): 197-203, 1991.

46. Malaty, H.M. et al.Transmission of $\mathrm{H}$ elicobacter pylori infection. Studies in families of healthy individuals. Scand. J. Gastroenterol., 26(9): 927-32, 1991.

47. Marschall, B.J. et al. Campylobacter pylori infection and gastroduodenal disease. Med. J.UST, 142:439-44, 1985.

48.Marschall,B.J.H elico bacter pylori in the year 2000. Helicobacter pylori Foundation, p. 1-9, 2000. Disponível em http:// www.helicobacter.com/hpy2k/frMain.htm.Acesso em 8/8/2001.

49. Mégraud, F. Microbiological characteristics of Campylobacter pylori. Eur. J. Gastroenterol. Hepatol., 1: 5-12, 1989.

50. Mello, E.S. \& Melo, C.R. Prevalência dos diferentes tipos de gastrite em pacientes com queixas digestivas altas. Arq. Gastroenterol., 29(2): 43-50, 1991.

51. N aito, Y. \& Yoshikawa, T. Molecular and cellular mechanisms involved in Helicobacter pylori-induced inflammation and oxidative stress. Free Radic. Biol. M ed., 33(3):323-36, 2002.

52. $O$ liveira, A.M.R. et al. Prevalence of $H$. pylori infection in a population from the rural area of A raçuaí, MG , Brazil. Rev. M icrobiol., 30(1): 59-61, 1999.

53. 0 ndebreit S. et al. Translocation of Helicobacter pylori cagA into gastric epithelial cells by type IV secretion. Science, 287: 1497-500, 2000

54. Parsonnet, J. et al. Risk for gastric cancer in people with cagA positive or cagA negative Helicobacter pylori infection. Gut, 40:297-301, 1997.

55. Peek, R.M.;M Mss,S.F.\&Tham, K.T. cagA + strains and dissociation of gastric epithelial proliferation from apoptosis. J. Natl. Cancer Inst., 89: 863-8, 1997.

56. Peek, R.M. et al. Helicobacter pylori strain-specific genotypes and modulation of the gastric epithelial cell cycle. Cancer Res., 59:6124-31, 1999.

57. Peterson, W.L. Review article: Helicobacter pylori and gastric adenocarcinoma.Aliment.Pharmacol.Ther,,16(suppl.1):40-6,2002.

58. Prinz, C. et al. Key importance of the Helicobacter pylori adherence factor blood group antigen binding adhesin during gastric inflammation. Cancer Res., 61:1174-80,2001.

59. Q ueiroz, D.M.M.\& Mendes, E.N .H . Helicobacter pylori e outros microorganismos espiralados gástricos:aspectos microbiológicos. In: Castro, L.P.; Rocha, P.R.S. \& Coelho, L.G.V. (eds.) Tópicos em gastroenterologia. São Paulo:Medsi, 1993.v. 4, p. 235-48.

60. Q ueiroz, D.M.M. et al. CagA-positive Helicobacter pylori and risk for developing gastric carcinoma in Brazil. Int. J. Cancer., 78: 135-9, 1998

61. Romaniuk, P.J. et al. Campylobacter pylori, the spiral bacterium asso ciated with human gastritis, is not a true Campylobacter sp. J. Bacteriol., 169(5): 2137-41, 1987.

62. Sakagami,T. et al. H ost factors in H elicobacter infection. Gut, 39: $639-48,1996$
63. Salama, N .R. et al.Vacuolating cytotoxin of Helicobacter pylori plays a role during colonization in a mouse model of infection. Infect. Immun., 69(2): 730-6, 2001.

64. Satin, B. et al.The neutrophil-activating protein (HP-N AP) of $\mathrm{H}$ elicobacter pylori is a protective antigen and a major virulence factor. J. Exp. M ed., 191(9): 1467-76, 2000.

65. Segal, E.D. et al. A ltered states: involvement of phosphorylated cagA in the induction of host cellular growth changes by H elicobacter pylori. Proc.N atl.Acad. Sci.USA, 96:14559-64,1999.

66. Sepúlveda, A.R. Molecular testing of Helicobacter pyloriassociated chronic gastritis and premalignant gastric lesions. J. Clin. Gastroenterol., 32(5): 377-82, 2001.

67.Sokol, R.J.\& H offenberg, E.J.A Antioxidantes na doença gastrointestinal pediátrica. Clin. Ped. Am. N orte, 8: 457-72, 1997.

68. Solari, C.A. et al. Helicobacter pylori in dyspeptic children and adults:endoscopic, bacteriologic and histologic correlations. M em. Inst. Oswaldo Cruz., 89(4): 581-6, 1994.

69. Souto, F..D. et al. Prevalence of Helicobacter pylori infection in a rural area of the state of Mato G rosso, Brazil. M em. Inst. Oswaldo Cruz, 93(2): 171-4, 1998.

70. Stein M.; Rappuoli R.\& Covacci A .Tyrosine pho sphorilation of the Helicobacter pylori cagA antigen after cag-driven host cell translocation. Proc. Natl.Acad. Sci.USA, 97:1263-8, 2000.

71. Sung J.J. et al. Cyclooxygenase-2 expression in Helicobacter pylori-associated premalignant and malignant gastric lesions. Am. J. Pathol., 157(3): 729-35, 2000.

72. Thomsen, L.L.; Gavin, B.J. \& Tasman-Jones, C. Relation of Helicobacter pylori to human gastric mucosa in chronic gastritis of the antrum. Gut, 32(1):230-6, 1990.

73.Tombola, F. et al.The H elicobacter pylori toxin is a urea permease that promote urea diffusion across epithelia. J. Clin. Invest., 108(6): 929-37, 2001.

74. Vandamme, P. et al. Revision of Campylobacter, Helicobacter, and Wolinella taxonomy: emendation of generic descriptions and proposal of Arcobacter gen. N ov. Int. J. Syst. Bacteriol., 41(1): 88-103, 1991

75.Van-D oorn, L.et al.C linical relevance of the cagA, vacA, iceA status of Helicobacter pylori. Gastroenterology, 115:59-66, 1998.

76. W alsh, J.H. A pH-sensitive channel regulates urea across to H elicobacter pylori urease.Gastroenterology,118:249-50,2000.

77. W arren, J.R. \& Marshall, B.J. U nidentified curved bacilli in the stomach of patients with gastritis and peptic ulceration. Lancet, 16 1(8390): 1311-5, 1984.

78. W eeks, D.L. et al. $\mathrm{H}^{+}$-gated urea channel: the link between Helicobacter pylori urease and gastric colonization. Science, 287: 482-5, 2000.

79.W eeks, D.L. \& Sachs, G. Sites of pH regulation of the urea channel of Helicobacter pylori. M ol. M icrobiol., 40(6): 1249-89, 2001.

80. Yamaoka Y. et al. Variants of the 3 ' region of the cagA gene in $\mathrm{H}$ elicobacter pylori iso lates from patients with different $\mathrm{H}$. pyloriassociated diseases. J Clin. M icrobiol., 36 (8): 2258-63, 1998.

\begin{tabular}{l|l} 
& Endereço para correspondência \\
\hline Maria Aparecida Marchesan Rodrigues \\
Departamento de Patologia \\
Faculdade de Medicina de Botucatu \\
Universidade Estadual Paulista \\
Rubião Júnior s/n - Rubião Júnior \\
CEP 18618-000 - Botucatu-SP
\end{tabular}

